\title{
Do Narcissists Self-Enhance? Disentangling the Associations Between Narcissism and Positive Versus Enhanced Self-Views Across Aspects of Narcissism, Content Domains, and Comparison Criteria
}

Ina Mielke ${ }^{1,2}$, Sarah Humberg ${ }^{1}$, Marius Leckelt ${ }^{3}$, Katharina Geukes ${ }^{1+}$ and Mitja D. Back ${ }^{1+}$

\author{
${ }^{1}$ University of Münster, Germany \\ ${ }^{2}$ University Medical Center Hamburg-Eppendorf \\ ${ }^{3}$ University of Mainz, Germany \\ + These authors share senior authorship
}

\section{in press, Social Psychological and Personality Science}

This is an unedited manuscript accepted for publication. The manuscript will undergo copyediting, typesetting, and review of resulting proof before it is published in its final form

Correspondence concerning this article should be addressed to Mitja D. Back (mitja.back@uni-muenster.de), University of Münster, Institute for Psychology, Psychological Assessment and Personality Psychology, Fliednerstr. 21, 48149 Münster, Germany. We are grateful to the many people who enabled us to implement the PILS and CONNECT studies.

Additional materials can be found in the OSF and are available during masked peerreview via the following link: http://go.wwu.de/5r-qw . OSF materials include a preregistration, anonymous data of both samples, $\mathrm{R}$ codes for the main analyses and the Supplemental Online Material (SOM). The SOM includes additional information on the statistical approach (Material A), descriptive statistics (Material B), internal consistencies and intercorrelations (Material C), analyses per domain and sample for admiration and rivalry (Material D) for the NPI and its facets (Material E). 
Author Information

Ina Mielke, M.Sc., is a researcher at the Institute of Biochemistry and Molecular Cell Biology, Workgroup Student Selection at University Medical Center Hamburg-Eppendorf.

Sarah Humberg, $\mathrm{PhD}$, is a researcher at the Department of Psychology, Psychological Assessment and Personality Psychology at the University of Münster.

Marius Leckelt, $\mathrm{PhD}$, is an assistant professor for Diagnostics and Personality Psychology at the Department of Psychology at the University of Mainz.

Katharina Geukes, $\mathrm{PhD}$, is a researcher at the Department of Psychology, Psychological Assessment and Personality Psychology at the University of Münster.

Mitja D. Back, PhD, is a professor for Psychological Assessment and Personality Psychology at the Department of Psychology at the University of Münster. 


\begin{abstract}
Across psychological disciplines, grandiose narcissism and self-enhancement have been treated as two closely related constructs. However, empirical research has not yielded conclusive insights about their association: It is currently unclear whether self-views of narcissistic individuals are more enhanced, in comparison with some criterion value, or whether their self-views are simply more positive than those of less narcissistic individuals. We aimed to clarify this fundamental issue with regard to (a) different aspects of narcissism (narcissistic admiration and rivalry), (b) different content domains of self-views (agency and communion), and (c) different criteria against which self-perceptions were compared (reputations, perceptions of others, objective criteria). We used data from two multimethodological studies $(N=420)$ and applied condition-based regression analyses, a statistical approach that is suitable for differentiating between self-enhancement and the mere positivity of self-views. Results contradicted general claims of narcissism as the "selfenhancer personality" and highlighted more specific patterns of narcissistic self-evaluations.
\end{abstract}

Keywords: grandiose narcissism, self-enhancement, positivity of self-view, conditionbased regression analysis 
Do Narcissists Self-Enhance? Disentangling the Associations Between Narcissism and Positive Versus Enhanced Self-Views Across Aspects of Narcissism, Content Domains, and

\section{Comparison Criteria}

For decades, grandiose narcissism and self-enhancement $(\mathrm{SE})^{1}$ have been treated as two closely related constructs. Narcissism has often been used as an indicator of SE (Paulhus, 1998), whereas SE has often been considered a crucial aspect of narcissism (e.g., Campbell, Reeder, Sedikides, \& Elliot, 2000; John \& Robins, 1994; Wallace, 2011). Narcissism has even been labeled the "self-enhancer personality" (Morf, Horvath, \& Torchetti, 2011, p. 399). Indeed, empirical studies have revealed a consistent positive, albeit small, correlation between narcissism and SE (Grijalva \& Zhang, 2015).

However, one important caveat has yet to be taken into account: When investigating the relation between narcissism and SE, it is crucial that individual differences in SE (i.e., how much the self-view exceeds a comparison criterion) are differentiated from individual differences in the mere positivity of self-views (PSV; i.e., how favorable the self-view is). With regard to a specific attribute (e.g., attractiveness), Person A (e.g., Albert, who rates his attractiveness as a 6 on a 10-point scale) scores higher on PSV than Person B (e.g., Betty with a self-view of 4) if Person A's self-view is more favorable. By contrast, to investigate SE, the self-view and a criterion need to be compared: Person A is typically considered to score higher on SE than Person B if Person A's self-view exceeds some criterion measure more (or trails less behind it) than Person B's self-view (e.g., Albert [self-view: 6, criterion: 3] has a higher level of SE [3] than Betty [self-view: 4, criterion: 2; SE = 2]). Accordingly, common operationalizations of SE involve directed discrepancy scores (e.g., the algebraic difference) between self-views and criterion measures (e.g., Alicke \& Sedikides, 2011).

The distinction between SE and PSV is generally acknowledged in the common definition and operationalization of SE. However, the statistical approaches that have been 
applied to analyze the empirical association between individual differences in SE and individual differences in third variables (e.g., narcissism) entangle SE and PSV correlates. These approaches consisted of two steps: In a first step, a SE score was determined for each person by computing an algebraic difference or residual score (e.g., SE score = self-view variable minus criterion variable). In the second step, the correlation between this SE score and the narcissism variable has been computed. The main problem of these two-step approaches is that in the first step, information from two variables (self-view and criterion) is reduced into a single score (e.g., the algebraic difference/residual), but the information that is lost during this procedure would be relevant for separating the association between narcissism and SE from the association between narcissism and PSV in the second step (when computing the correlation). As a consequence, the correlation between an SE score and narcissism will be positive if SE is in fact related to narcissism, but also if only one of the constituents of the SE score (e.g., the self-view) is related to narcissism. In other words, a positive correlation cannot tell whether Albert's higher narcissism as opposed to Betty's lower narcissism has to do with his higher SE score or with the simpler fact that he views himself more positively. Accordingly, previous approaches are systematically biased and lead researchers to conclude that narcissism is related to SE even when this is not the case, namely when narcissism is instead only related to PSV (for more detailed elaborations, see, e.g., Asendorpf \& Ostendorf, 1998; Edwards \& Parry, 1993; Humberg et al., 2018a; Griffin, Murray, \& Gonzalez, 1999; Krueger \& Wright, 2011) $)^{2}$. Consequently, despite the large body of research, it remains unknown whether narcissists indeed self-enhance more than others or whether they simply hold more positive self-views.

With the present research, we aimed at taking a fresh look at narcissistic SE. Specifically, we used condition-based regression analysis (CRA; Humberg et al., 2018a, 2018b), which enabled us to differentiate the relation between narcissism and SE from the 
relation between narcissism and PSV. The key idea behind the CRA is to avoid the loss of information that is inherent in two-step approaches. Instead, one inserts all information about the self-view and the criterion variable separately into a multiple regression analysis in which narcissism is simultaneously regressed on the self-view and the criterion measure, and inspects the constellation of the estimated regression coefficients. In applying the CRA, we considered (a) different aspects of narcissism, (b) different content domains of self-views, and (c) different kinds of criteria against which self-perceptions were compared.

First, we differentiated between two aspects of grandiose narcissism. Whereas grandiose narcissism has traditionally been conceptualized as a one-dimensional construct, a growing body of research has called for its differentiation into moderately correlated agentic (narcissistic admiration) and antagonistic (narcissistic rivalry) aspects (e.g., Back et al., 2013; Back, 2018; Crowe, Lynam, Campbell, \& Miller, 2019; Wright \& Edershile, 2018). The agentic aspect, narcissistic admiration, refers to individual differences in the tendency to employ a self-promotional social strategy and the tendency to engage in self-assured, expressive behaviors and self-presentation. The antagonistic aspect, narcissistic rivalry, refers to differences in the tendency to apply a self-defensive strategy and to engage in arrogant, combative behaviors and other-derogation.

Second, we considered SE and PSV with respect to agentic and communal content domains. Previous research has indicated that individuals high in narcissism tend to particularly value their attributes in domains such as physical attractiveness (Bleske-Rechek, Remiker, \& Baker, 2008; Gabriel, Critelli, \& Ee, 1994), intelligence (e.g., Gabriel et al., 1994), and leader-like status (Grijalva, Harms, Newman, Gaddis, \& Fraley, 2015; Judge, LePine, \& Rich, 2006), that is, regarding agentic characteristics. This should predominantly hold for admiration, the agentic aspect of grandiose narcissism. Rivalry, by contrast, was even found to be related to more negative self-views, particularly in the communal domain (e.g., 
honesty, empathy, courtesy; Back et al., 2013; Kwiatkowska, Jułkowski, Rogoza, ŻemojtelPiotrowska, \& Fatfouta, 2019; Mota et al., 2019). Therefore, we explored whether narcissism's associations with SE and PSV, respectively, vary across agentic and communal content domains. We expected potential associations with admiration to be stronger for agentic domains and potential associations with rivalry to be stronger for communal domains (these general expectations were pre-registered, see http://go.wwu.de/5r-qw).

Third, to operationalize SE, we considered three criteria to which self-reports have typically been compared: reputations (i.e., acquaintances' reports about a target; Kwan, John, Robins, \& Kuang, 2008; Paulhus, 1998), targets' perceptions of others (i.e., perceiver effects; Kwan et al., 2008; Brown, 1986), and objective criteria (i.e., psychometric tests or ratings of trained coders; Bleske-Rechek et al., 2008; Gabriel et al., 1994). Here, we applied all three criteria and explored potential differences in narcissism's associations with them.

\section{Method}

We integrated data from a laboratory and a field study to examine potential relations between narcissism and SE or PSV. Both samples consisted of university students and included similar or identical measures of narcissism, self-perceptions, and the three types of criteria.

A simulation study (see http://go.wwu.de/5r-qw for the code) to investigate the power of the CRA indicated that with our sample of size $N=420$, we were able to detect a small SE effect $\left(\mathrm{R}^{2}=.04\right)$ with a power between $83 \%$ and $92 \%$ (depending on the correlation between the self-view and criterion) and a moderate SE effect $\left(\mathrm{R}^{2}=.10\right)$ with a power of $100 \%$ (irrespective of the correlation).

\section{Sample 1: Laboratory Study}

Data were provided by university students participating in a longitudinal laboratory study (authors, 2019; see codebook at [blinded] for a comprehensive description). Starting with an initial sample of 311, a total of 297 (162 female) participants with an average age of 
23.81 years ( $S D=3.96$, Range: 18 to 39$)$ completed the requested narcissism measures. An overview of the procedures can be found in Figure 1.

Measures. Whenever more than one rater or time point was available, items were first aggregated across raters, second across time points, and, third, into the final variable. For all aggregations, we first $z$-standardized the items and then computed their average value for each participant. Agentic measures always included aspects of intelligence, attractiveness, and leadership. Communal measures always included prosocial aspects. Detailed information on each variable can be found in Table 1.

Narcissism. Participants completed the 18-item version of the Narcissistic Admiration and Rivalry Questionnaire (NARQ; Back et al., 2013) on 6-point Likert scales, ranging from 1 (do not agree at all) to 6 (agree completely). The NARQ includes nine items for each aspect of narcissism, namely admiration and rivalry. Moreover, to provide supplementary results for a more traditional measure of narcissism, participants also completed the 40 -item version of the Narcissistic Personality Inventory (NPI; Raskin, \& Hall, 1979; Schütz, Marcus, \& Sellin, 2004).

Self-views. Participants' self-views of their agentic and communal traits were assessed with items from the Self-Attributes Questionnaire (SAQ; Pelham \& Swann, 1989) and some additional self-generated items. Participants were asked to rank themselves in comparison with their fellow students on a scale ranging from 1 (bottom 5\%) to 10 (uppermost 5\%) regarding several characteristics.

Reputations. Acquaintances (on average 2.03 per person, $S D=0.45$ ) completed an informant report that was parallel to the self-view questionnaire and were requested to compare the participant's characteristics with those of his or her fellow students on the identical SAQ items. Rating scales ranged from 1 (bottom 5\%) to 10 (uppermost 5\%). 
Perceptions of others. During the three group sessions, each participant rated all other group members on their agentic and communal properties at 10 time points in a round-robin design. The answers were given on rating scales, ranging from 1 (does not apply at all) to 6 (applies perfectly). For each variable, aggregates of group-mean-centered actor effects (i.e., how participants perceived their group members on average) across all time points were computed.

Objective criteria. An agentic variable was created by aggregating an intelligence test score, attractiveness ratings, and behavior ratings. The intelligence test score based on an aggregate of three computer-based intelligence tests (Raven; Denissen, Schönbrodt, van Zalk, Meeus, \& van Aken, 2011; MWT-B; Lehrl, 1995; WMC; Oberauer, Süß, Schulze, Wilhelm, \& Wittmann, 2000). Attractiveness was evaluated by six raters from portrait and full-body photographs on scales ranging from 1 (low expression on the item) to 10 (high expression on the item). Behavior was rated by three (first two tasks) or six (last four tasks) female raters of the videotaped interaction tasks on scales ranging from 1 (low expression on the item) to 6 (high expression on the item). The behavioral ratings were also used to obtain an objective communal variable.

\section{Sample 2: Field Study}

An initial sample of 131 psychology freshmen was reduced to a final sample of 123 (100 female) participants due to missing data on the narcissism measures (authors, 2019; see codebook at [blinded] for a comprehensive description). The average age of the final sample was 21.33 years $(S D=3.96$, Range: 18 to 42$)$. See Figure 1 for an overview of the procedures.

Measures. Item aggregation in Sample 2 was performed as in Sample 1. Content of agentic and communal measures tapped the same aspects as in Sample 1 and detailed information on each variable can be found in Table 1. 
Narcissism. As in Sample 1, narcissism was assessed with the 18-item version of the NARQ (Back et al., 2013) and the 40-item version of the NPI (Raskin, \& Hall, 1979; Schütz et al., 2004).

Self-views. Participants' agentic and communal self-views were assessed as in Sample 1. However, both variables were expanded by one more item each.

Reputations. Acquaintances (on average $M=2.29$ per person, $S D=1.03$ ) completed an informant version of the self-view questionnaire.

Perceptions of others. Personality assessments of fellow students in the diary began with the stem "This person is" and were rated on 11-point bipolar Likert scales. For each attribute, actor effects of each participant were aggregated across the seven time points.

Objective criteria. Objective scores regarding participants' intelligence were assessed as in Sample 1 with the same scales applied. Attractiveness was rated by three male and two female raters from photos. Behavior was rated by two male and five female raters from videos of the self-introduction. 


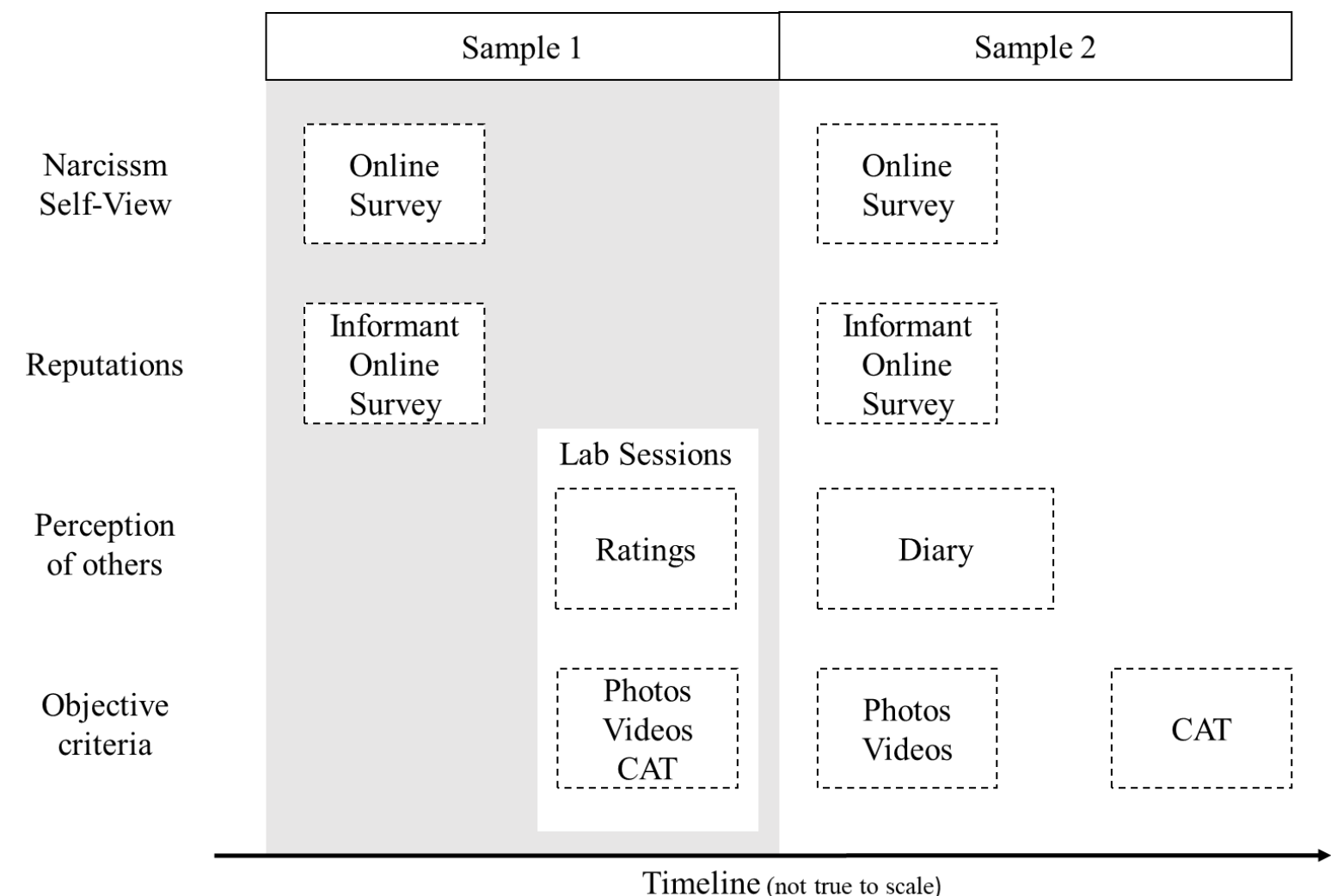

Figure 1. The figure describes the process of data collection for Sample 1 and Sample 2. Each dashed box reflects a source of data and is sorted according to the intended measure (see variables on the left) and the approximate chronology (see timeline on the bottom). In Sample 1, a first laboratory session followed about three weeks after participants and their acquaintances responded to corresponding versions of an online survey. Across three sessions, groups of four to six previously unacquainted participants performed seven videotaped and audiorecorded interaction tasks. Before and after each task, participants were asked to rate themselves and their group members on different attributes. At the end of the first session, photographs were taken and participants completed three cognitive ability tests. Data collection in Sample 2 started with an introductory session where photographs and videotaped self-introductions were taken. One week after, participants and their acquaintances responded to online surveys. During their first semester, participants answered a repeated online diary within seven biweekly assessments. In the diary, participants had to rate all fellow students they had interacted with in the last week on different attributes. Approximately one year after this first wave, participants completed three cognitive ability tests. CAT $=$ Cognitive Ability Tests. 
Table 1. Overview of Variables

\begin{tabular}{|c|c|c|c|c|c|}
\hline \multirow{2}{*}{ Study } & \multirow{2}{*}{$\begin{array}{l}\text { Content } \\
\text { Domain }\end{array}$} & \multirow{2}{*}{ Self-Views } & \multicolumn{3}{|c|}{ Agency and Communion Criteria } \\
\hline & & & Reputations & Perception of others & Objective criteria \\
\hline \multirow[t]{5}{*}{ Sample 1} & Agency & & & & \\
\hline & Intelligence & $\begin{array}{l}\text { intellectual/academic } \\
\text { ability, reasoning, } \\
\text { vocabulary, working } \\
\text { memory }\end{array}$ & $\begin{array}{l}\text { intellectual/academic } \\
\text { ability, reasoning, } \\
\text { vocabulary, } \\
\text { working memory }\end{array}$ & intelligence & Raven, MWT-B, WMC \\
\hline & Attractiveness & face, body, clothes & face, body, clothes & attractiveness & $\begin{array}{l}\text { face, body, modern } \\
\text { clothes, neat clothes }\end{array}$ \\
\hline & Leadership & $\begin{array}{l}\text { leadership ability, } \\
\text { assertive }\end{array}$ & $\begin{array}{l}\text { leadership ability, } \\
\text { assertive }\end{array}$ & leadership,assertiveness & $\begin{array}{l}\text { expressive behavior, } \\
\text { dominant behavior }\end{array}$ \\
\hline & Communion & $\begin{array}{l}\text { helpful, sensitive, } \\
\text { trustworthy, } \\
\text { honest }\end{array}$ & $\begin{array}{l}\text { helpful, sensitive, } \\
\text { trustworthy, } \\
\text { honest }\end{array}$ & trustworthiness & cooperative behavior \\
\hline \multirow[t]{5}{*}{ Sample 2} & Agency & & & & \\
\hline & Intelligence & $\begin{array}{l}\text { intellectual/academic } \\
\text { ability, } \\
\text { reasoning, vocabulary, } \\
\text { working memory }\end{array}$ & $\begin{array}{l}\text { intellectual/academic } \\
\text { ability, reasoning, } \\
\text { vocabulary, working } \\
\text { memory }\end{array}$ & unintelligent - intelligent & Raven, MWT-B, WMC \\
\hline & Attractiveness & face, body, clothes & face, body, clothes & unattractive - attractive & $\begin{array}{l}\text { face, body, modern } \\
\text { clothes, neat clothes }\end{array}$ \\
\hline & Leadership & $\begin{array}{l}\text { leadership ability, } \\
\text { assertive, dominant }\end{array}$ & $\begin{array}{l}\text { leadership ability, } \\
\text { assertive, dominant }\end{array}$ & submissive - dominant & $\begin{array}{l}\text { expressiveness, self- } \\
\text { confidence }\end{array}$ \\
\hline & Communion & $\begin{array}{l}\text { helpful, sensitive, } \\
\text { trustworthy, } \\
\text { honest, affectionate }\end{array}$ & $\begin{array}{l}\text { helpful, sensitive, } \\
\text { trustworthy, } \\
\text { honest, affectionate }\end{array}$ & $\begin{array}{l}\text { coldhearted - affectionate, } \\
\text { critical - warmhearted }\end{array}$ & friendliness \\
\hline
\end{tabular}

Note. Raven = 15-item version of Raven's Progressive Matrices test (Denissen, Schönbrodt, van Zalk, Meeus, \& van Aken, 2011), MWT-B =

Mehrfachwahl-Wortschatz-Intelligenztest (Lehrl, 1995), WMC = Working Memory Capacity test (Oberauer, Süß, Schulze, Wilhelm, \&

Wittmann, 2000). 


\section{Statistical Approach}

We applied condition-based regression analysis (CRA; Humberg et al., 2018a, 2018b) to test the association between narcissism and SE (for reproducible code and data for all analyses, see http://go.wwu.de/5r-qw). CRA has recently been introduced as an approach that enables testing this kind of effect while avoiding the limitations of two-step approaches that had traditionally been used to achieve this aim. The CRA approach is suitable for testing how narcissism is associated with SE and PSV in one step and for differentiating these associations from one another (for an application of CRA in a similar research domain, see Mota et al., 2019). Specifically, a linear regression model in which participants' narcissism scores are regressed on their self-views and criterion measures is estimated:

narcissism $=c_{0}+c_{1} *$ self-view $+c_{2} *$ criterion $+\varepsilon$.

According to the CRA, the constellation of the self-view and criterion coefficients must be inspected to determine whether the model indicates an association between narcissism and SE. Narcissism relates to SE if, and only if, the self-view coefficient is significantly positive (i.e., for two individuals with the same criterion score, the person with the higher self-view score, who thus self-enhances more, is more narcissistic) and the criterion coefficient is significantly negative (for two individuals with the same self-view score, the person with the lower criterion score, who thus self-enhances more, is more narcissistic). Instead of testing the self-view and criterion coefficients separately, Humberg et al. (2018a) recommended using an equivalent set of conditions:

$a b s=\left|c_{1}-c_{2}\right|-\left|c_{1}+c_{2}\right|>0$

and $\left(c_{1}-c_{2}\right)>0$.

To infer that there is a positive association between narcissism and SE, the first condition must be significant, and the second condition must hold numerically. If at least one condition 
is violated, the data do not indicate a significant relation between narcissism and SE for the current set of variables (for more information, see SOM at http://go.wwu.de/5r-qw).

A graphical illustration of a model that satisfies the two conditions is provided in the left panel of Figure 2. The figure demonstrates that for such a model, people with the highest model-predicted narcissism scores (i.e., the highest values on the vertical axis; see the highest, dark green part of the regression surface) are the people who hold a high self-view while having a low criterion score, that is, who have the highest possible SE level.

When the estimated regression model contradicted a relation between narcissism and SE, we tested whether narcissism was instead related to PSV. As PSV only refers to people's self-views irrespective of their criterion scores, solely the coefficient $c_{l}$ of the self-view variable had to be considered. A positive association between narcissism and PSV (controlled for the respective criterion variable) was reflected in a significantly positive $c_{1}$ coefficient. Specifically, one can conclude that narcissism relates to PSV but not to SE if $c_{1}$ is significant, whilst $a b s$ is not significantly positive. The right panel of Figure 2 shows the graph of a model that contradicts an association between narcissism and SE but shows a positive relation with PSV instead. People with the highest narcissism scores are those who hold a high self-view regardless of their criterion score and thus regardless of their level of SE (see the highest, dark green part of the surface). Finally, a negative association between narcissism and PSV would be indicated by a significantly negative $c_{1}$ coefficient. In this case, people with higher narcissism scores hold less favorable self-views.

All analyses were performed using R version 3.4.2 (R Core Team, 2017), and the regression models were estimated using the sem function from the R package lavaan (version 0.5-12 beta; Rosseel, 2012). To meta-analytically integrate the regression weights across the two samples, we applied the multivariate generalized least squares approach (Becker \& Wu, 2017). That is, coefficients were first estimated separately for each sample and contributed in 
a standard-error-weighted way to the meta-analytical coefficients. Main analyses were performed separately for each combination of the distinctions, namely (a) narcissistic admiration and rivalry, (b) agency and communion, and (c) three comparison criteria, resulting in $2 \times 2 \times 3=12$ analyses. Additional analyses were performed with the NPI as the narcissism measure. Sample sizes for different criteria varied slightly due to dropouts and randomly missing data (see SOM at http://go.wwu.de/5r-qw).
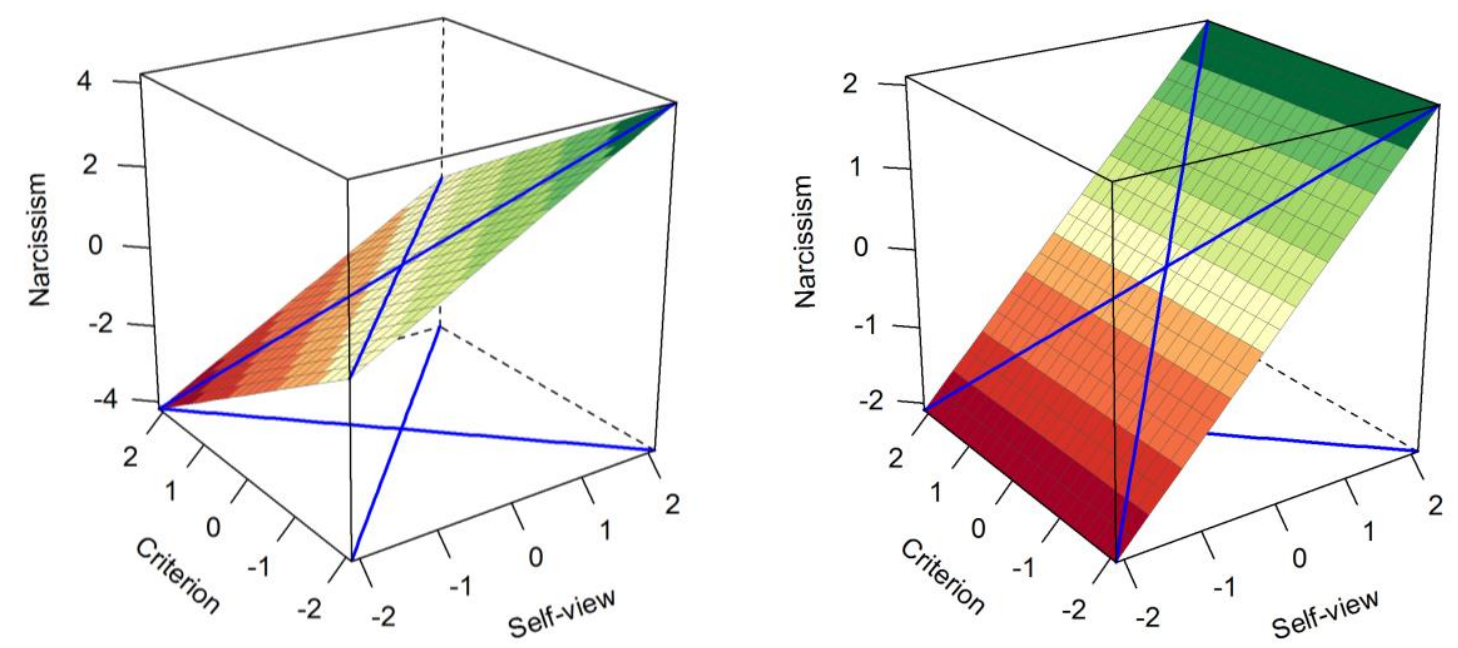

Figure 2. Graphs of the regression model narcissism $=c_{0}+c_{1} *_{\text {self-view }}+c_{2} *$ criterion $+\varepsilon$ for two different constellations of the coefficients $c_{1}$ and $c_{2}$. The model on the left $\left(c_{1}=1\right.$, $\left.c_{2}=-1\right)$ indicates a positive association between narcissism and SE; the model on the right $\left(c_{1}=1, c_{2}=0\right)$ indicates a positive association between narcissism and PSV.

\section{Results}

Table 2 provides information on the internal consistencies and intercorrelations for all measures in both samples. In Table 3, we provide the standardized coefficients of the CRA, along with $95 \%$ confidence intervals and levels of significance, the index $a b s$, and interpretations of the combinations of the coefficients (for separate results regarding the single samples, single agentic domains, and NPI facets, see SOM at http://go.wwu.de/5r-qw). 
Graphical illustrations of the resulting regression models for admiration and rivalry can be found in Figures 3 to 5.

A positive association between narcissism and SE was present in four out of the 12 main CRAs. Admiration was positively associated with SE when comparing self-views of agency and communion with corresponding reputations. That is, the higher individuals scored on admiration, the more their self-viewed agentic and communal characteristics exceeded the respective ratings by acquaintances. Rivalry was found to be positively associated with SE when comparing self-views of agency with reputations and with participants' perceptions of others. Thus, the higher individuals scored on rivalry, the more their self-viewed agentic characteristics exceeded the ratings by acquaintances and their general perception of others' agentic characteristics, respectively. The abs parameter was not significant in any of the other analyses, which means that narcissism was not significantly related to SE for the eight other combinations of the aspects of narcissism, content domains, and criterion variables.

For the remaining eight analyses, we considered the coefficient $c_{1}$ to determine whether narcissism was instead related to PSV. Results indeed showed that admiration was positively associated with PSV regarding agency and communion when controlling for participants' perceptions of others or for the objective criteria, respectively. Independent of the domain of interest and when statistically controlling for one of the two criteria, individuals who scored higher on admiration tended to hold more positive self-views. This relation seemed to be stronger for agentic characteristics ( $c_{1}=0.54$ for all criteria) than for communal characteristics (reputations: $c_{1}=0.13$, perceptions of others: $c_{1}=0.11$, the objective criteria: $c_{1}$ $=0.12$ ).

A more nuanced pattern resulted for rivalry. Rivalry was consistently negatively related to PSV regarding communal characteristics when controlling for one of the three criteria. In other words, individuals with higher levels of rivalry judged their own communal 
characteristics as more negative than people with lower rivalry levels, independent of their actual communal characteristics. For agentic characteristics, by contrast, there was a positive relation between rivalry and PSV when the objective criteria were controlled for.

In sum, in all analyses in which narcissism was not significantly associated with SE, narcissism was significantly related to PSV when controlling for the respective criterion. These relations were quite different between the two aspects of narcissism we considered: Whereas the relations between admiration and PSV were consistently positive and stronger for agentic characteristics, rivalry showed a consistent negative relation to PSV for communal characteristics. Additional results for the NPI were less differentiated and showed no relations to SE but positive relations to PSV for agentic characteristics that were comparable high as for admiration. Besides our focal results, narcissism was also associated with some of the considered criterion measures (indicated by a significant coefficient $c_{2}$; see SOM D for a summary). 
Table 2. Internal Consistencies and Intercorrelations for Narcissistic Admiration and Rivalry, Self-View, and Criteria Measures

\begin{tabular}{|c|c|c|c|c|c|c|c|c|c|c|c|c|c|}
\hline & $\alpha_{1}$ & $\alpha_{2}$ & 1. & 2. & 3. & 4. & 5. & 6. & 7. & 8. & 9. & 10. & 11. \\
\hline 1. NARQ Admiration & .82 & .79 & - & .33 & .67 & .56 & .10 & .06 & -.19 & -.01 & -.01 & .21 & .00 \\
\hline 2. NARQ Rivalry & .78 & .76 & .23 & - & .34 & .13 & -.16 & -.03 & -.22 & -.16 & -.16 & -.03 & -.14 \\
\hline 3. NPI & .79 & .77 & .57 & .16 & - & .60 & .03 & .16 & -.16 & -.10 & -.13 & .25 & -.01 \\
\hline
\end{tabular}

Self-views

\begin{tabular}{|c|c|c|c|c|c|c|c|c|c|c|c|c|c|}
\hline 4. Agency & - & - & .44 & .04 & .50 & - & .30 & .26 & -.07 & -.08 & -.12 & .32 & .06 \\
\hline 5. Communion & .79 & .83 & .15 & -.06 & -.03 & .35 & - & .09 & .12 & .10 & .08 & -.05 & -04 \\
\hline
\end{tabular}

Reputations

\begin{tabular}{|c|c|c|c|c|c|c|c|c|c|c|c|c|c|}
\hline 6. Agency & - & - & -.01 & -.15 & .14 & .26 & -.03 & - & .48 & -.09 & -.10 & .35 & .08 \\
\hline 7. Communion & .88 & .88 & -.12 & -.19 & -.10 & -.06 & .08 & .39 & - & .07 & -.01 & .10 & .02 \\
\hline \multicolumn{14}{|c|}{ Perceptions of others } \\
\hline 8. Agency & - & - & .19 & -.16 & .07 & -.14 & -.07 & -.06 & -.02 & - & .82 & -.06 & .14 \\
\hline 9. Communion & .97 & .89 & .08 & -.16 & -.08 & -.10 & .13 & -.07 & -.02 & .69 & - & .04 & .18 \\
\hline \multicolumn{14}{|l|}{ Objective criteria } \\
\hline 10. Agency & - & - & -.06 & .05 & .11 & .10 & -.12 & .22 & .08 & .44 & .22 & - & .44 \\
\hline 11. Communion & .85 & - & .14 & .06 & .21 & .07 & .07 & .04 & -.02 & .18 & -.10 & .54 & - \\
\hline
\end{tabular}

Note. The first two columns contain Cronbach's Alpha for Sample 1 and Sample 2, respectively. Please note that Cronbach's Alphas were not the adequate choice in the cases of the agency aggregates. In these cases, we aggregated across different aspects of agency and not across indicators that are thought to be indistinguishable (see Asendorpf, 1988, for a similar reasoning in the case of behavioral aggregates). The objective criterion for communion in Sample 2 was a single item and, therefore, Cronbach's Alpha is not provided. The upper triangle contains intercorrelations for Sample 1 and the lower triangle for Sample 2. Bold correlations are significant at $p<.05$ or at more extreme $p$-values. 
Table 3. Meta-Integrated Condition-Based Regression Analysis Parameters for Narcissistic Admiration and Rivalry and the Narcissistic Personality Inventory

\begin{tabular}{|c|c|c|c|c|c|c|c|c|c|c|c|c|}
\hline \multirow{2}{*}{ Criteria } & \multicolumn{4}{|c|}{ Admiration } & \multicolumn{4}{|c|}{ Rivalry } & \multicolumn{4}{|c|}{ NPI } \\
\hline & Coefficient & $95 \% \mathrm{CI}$ & $p$ & Interpret & Coefficient & $95 \% \mathrm{CI}$ & $p$ & Interpret & Coefficient & $95 \% \mathrm{CI}$ & $p$ & Interpret \\
\hline \multicolumn{13}{|l|}{ Reputations } \\
\hline \multicolumn{13}{|l|}{ Agency } \\
\hline $\mathrm{c}_{1}$ & 0.54 & {$[0.45 ; 0.62]$} & $<.001$ & & 0.13 & {$[0.03 ; 0.23]$} & .011 & & 0.56 & {$[0.48 ; 0.64]$} & $<.001$ & Pos. PSV \\
\hline $\mathrm{c}_{2}$ & -0.10 & {$[-0.18 ;-0.01]$} & .023 & & -0.10 & {$[-0.20 ; 0.00]$} & .057 & & 0.01 & {$[-0.07 ; 0.09]$} & .808 & \\
\hline abs & 0.20 & {$[0.05 ; \infty)$} & .012 & Pos. SE & 0.19 & {$[0.03 ; \infty)$} & .028 & Pos. SE & -0.02 & {$[-0.16 ; \infty)$} & .596 & \\
\hline \multicolumn{13}{|l|}{ Communion } \\
\hline $\mathrm{c}_{1}$ & 0.13 & {$[0.03 ; 0.22]$} & .008 & & -0.11 & {$[-0.20 ;-0.02]$} & .021 & Neg. PSV & 0.02 & {$[-0.08 ; 0.11]$} & .746 & \\
\hline $\mathrm{c}_{2}$ & -0.18 & {$[-0.28 ;-0.09]$} & $<.001$ & & -0.20 & {$[-0.30 ;-0.11]$} & $<.001$ & & -0.15 & {$[-0.24 ;-0.05]$} & .003 & \\
\hline abs & 0.25 & {$[0.10 ; \infty)$} & .004 & Pos. SE & -0.22 & {$[-0.38 ; \infty)$} & .990 & & 0.03 & {$[-0.13 ; \infty)$} & .373 & \\
\hline \multicolumn{13}{|c|}{ Perception of Others } \\
\hline \multicolumn{13}{|c|}{ Agency } \\
\hline $\mathrm{c}_{1}$ & 0.54 & {$[0.44 ; 0.64]$} & $<.001$ & Pos. PSV & 0.10 & {$[-0.02 ; 0.21]$} & .095 & & 0.58 & {$[0.48 ; 0.67]$} & $<.001$ & Pos. PSV \\
\hline $\mathrm{c}_{2}$ & 0.08 & {$[-0.02 ; 0.17]$} & .102 & & -0.15 & {$[-0.26 ;-0.05]$} & .005 & & -0.02 & {$[-0.11 ; 0.07]$} & .626 & \\
\hline abs & -0.16 & {$[-0.31 ; \infty)$} & .949 & & 0.19 & {$[0.00 ; \infty)$} & .048 & Pos. SE & 0.05 & {$[-0.11 ; \infty)$} & .313 & \\
\hline \multicolumn{13}{|l|}{ Communion } \\
\hline $\mathrm{c}_{1}$ & 0.11 & {$[0.00 ; 0.22]$} & .042 & Pos. PSV & -0.11 & {$[-0.22 ; 0.00]$} & .040 & Neg. PSV & -0.01 & {$[-0.12 ; 0.10]$} & .865 & \\
\hline $\mathrm{c}_{2}$ & 0.00 & {$[-0.11 ; 0.11]$} & .951 & & -0.15 & {$[-0.26 ;-0.04]$} & .005 & & -0.12 & {$[-0.23 ;-0.01]$} & .027 & \\
\hline abs & 0.01 & {$[-0.18 ; \infty)$} & .476 & & -0.23 & {$[-0.41 ; \infty)$} & .980 & & -0.02 & {$[-0.20 ; \infty)$} & .568 & \\
\hline \multirow{2}{*}{\multicolumn{13}{|c|}{$\begin{array}{l}\text { Objective Criteria } \\
\text { Agency }\end{array}$}} \\
\hline & & & & & & & & & & & & \\
\hline $\mathrm{c}_{1}$ & 0.54 & {$[0.44 ; 0.64]$} & $<.001$ & Pos. PSV & 0.16 & {$[0.04 ; 0.27]$} & .007 & Pos. PSV & 0.56 & {$[0.47 ; 0.66]$} & $<.001$ & Pos. PSV \\
\hline $\mathrm{c}_{2}$ & 0.01 & {$[-0.09 ; 0.10]$} & .892 & & -0.05 & {$[-0.16 ; 0.06]$} & .386 & & 0.07 & {$[-0.02 ; 0.16]$} & .136 & \\
\hline abs & -0.01 & {$[-0.17 ; \infty)$} & .554 & & 0.10 & {$[-0.09 ; \infty)$} & .193 & & -0.14 & {$[-0.29 ; \infty)$} & .932 & \\
\hline \multicolumn{13}{|l|}{ Communion } \\
\hline $\mathrm{c}_{1}$ & 0.12 & {$[0.03 ; 0.22]$} & .014 & Pos. PSV & -0.13 & {$[-0.23 ;-0.03]$} & .008 & Neg. PSV & 0.01 & {$[-0.09 ; 0.10]$} & .894 & \\
\hline $\mathrm{c}_{2}$ & 0.04 & {$[-0.05 ; 0.14]$} & .388 & & -0.08 & {$[-0.17 ; 0.02]$} & .103 & & 0.06 & {$[-0.04 ; 0.15]$} & .240 & \\
\hline abs & -0.09 & {$[-0.25 ; \infty)$} & .806 & & -0.16 & {$[-0.32 ; \infty)$} & .948 & & -0.01 & {$[-0.18 ; \infty)$} & .553 & \\
\hline
\end{tabular}

Note. Standardized coefficients for the following equation are shown: narcissism $=c_{0}+c_{1} *$ self-view $+c_{2} *$ criterion $+\varepsilon$. Pos. $/ \mathrm{Neg}$. PSV $=$

Positive/negative association between narcissism and the Positivity of Self-Views; Pos. SE = Positive association between narcissism and Self-

Enhancement; Interpret $=$ Interpretation of the parameters. The $p$ for $c_{1}$ and $c_{2}$ is two-tailed and the $p$ for $a b s$ is one-tailed. 


\section{Agency}

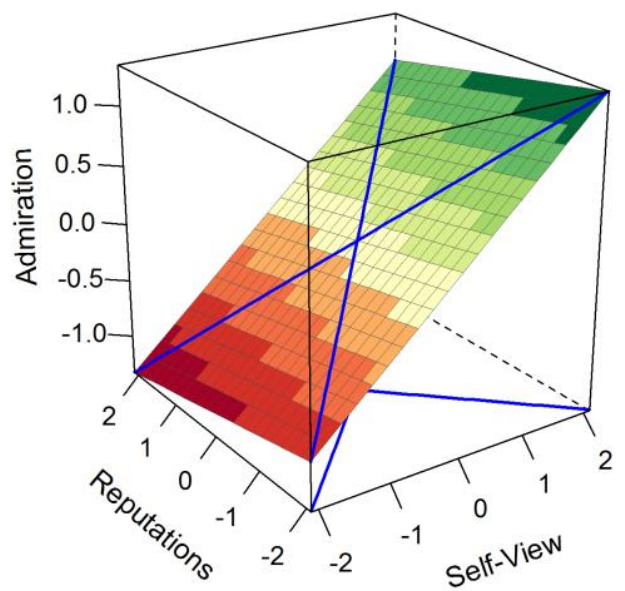

(a) Positive relation between Admiration and SE for Agency.

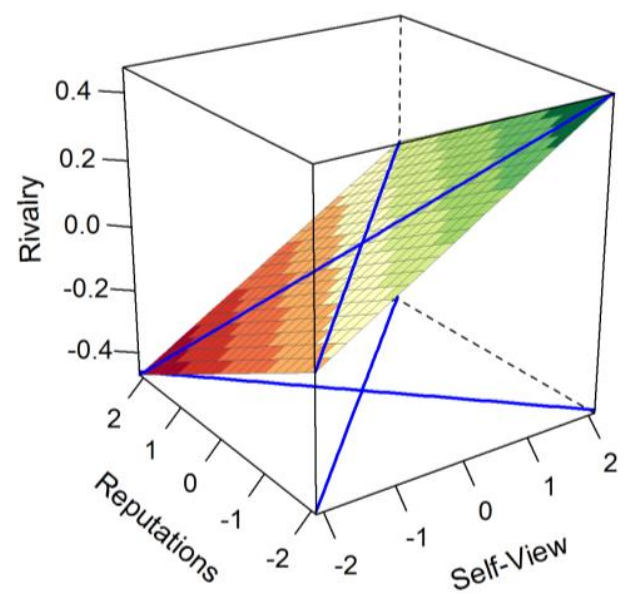

(c) Positive relation between Rivalry and SE for Agency.
Communion

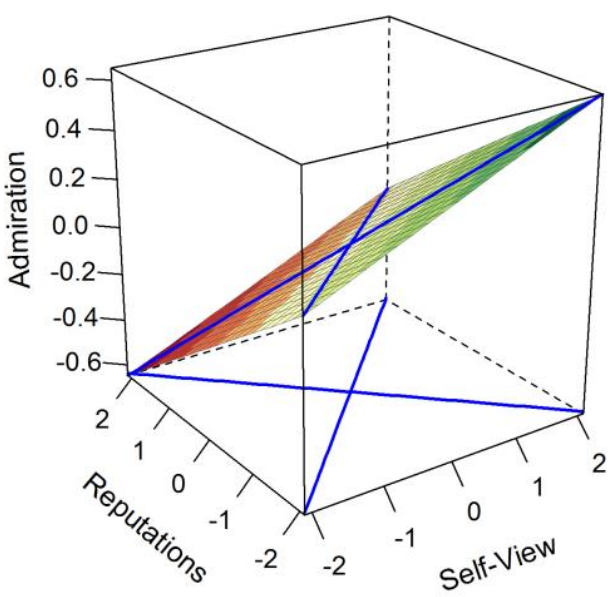

(b) Positive relation between Admiration and SE for Communion.

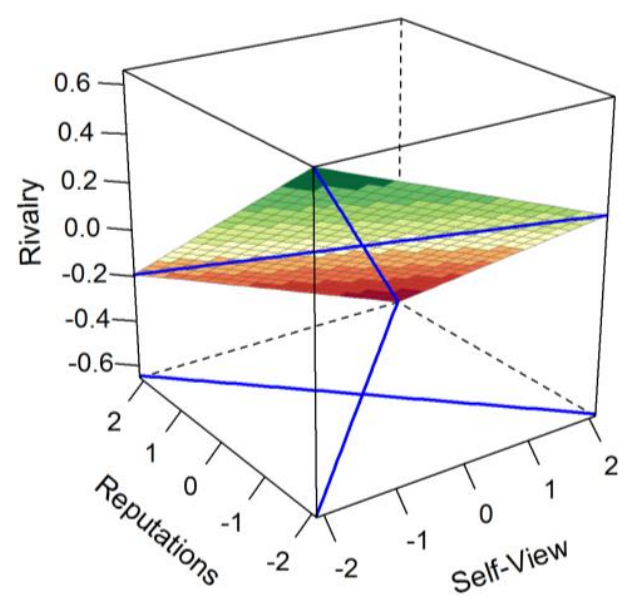

(d) Negative relation between Rivalry and PSV (and Reputations) for Communion.

Figure 3. Plotted regression surfaces of the CRA using reputations as the criterion (i.e., narcissism $=c_{0}+c_{1} *$ self-view $+c_{2} *$ reputations $+\varepsilon$ ). 


\section{Agency}

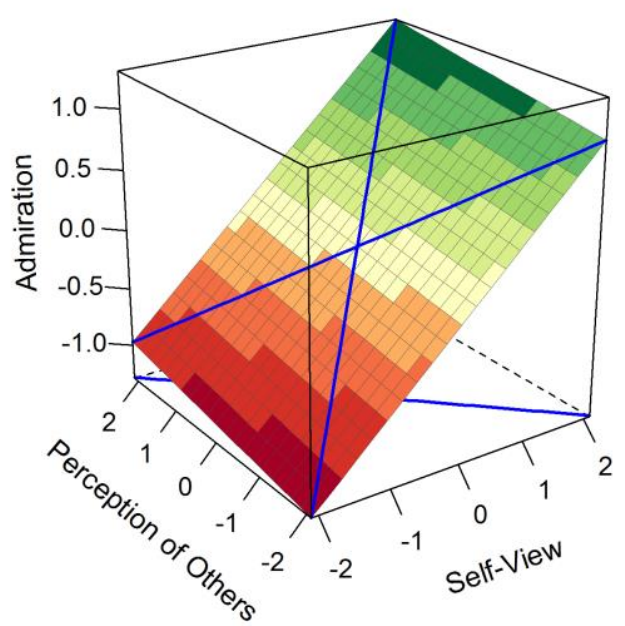

(a) Positive relation between Admiration and PSV for Agency.

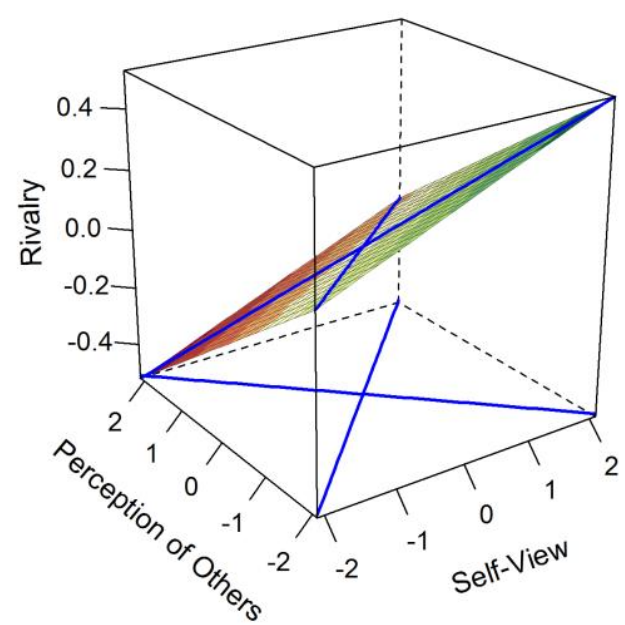

(c) Positive relation between Rivalry and SE for Agency.

\section{Communion}

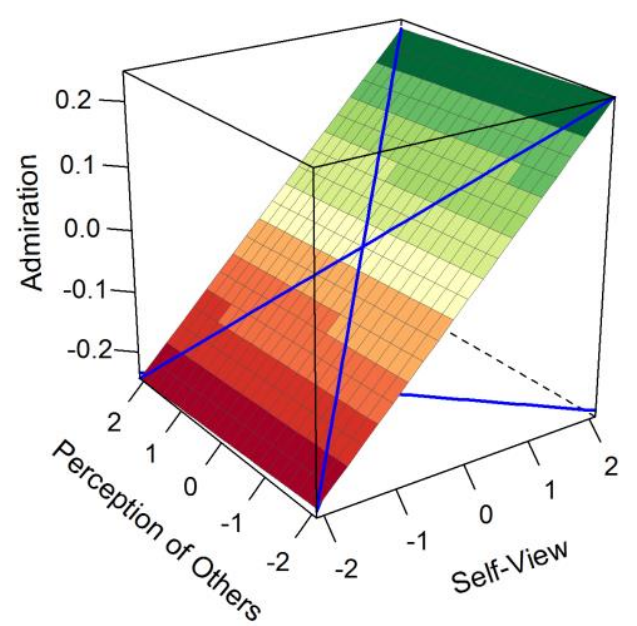

(b) Positive relation between Admiration and PSV for Communion.

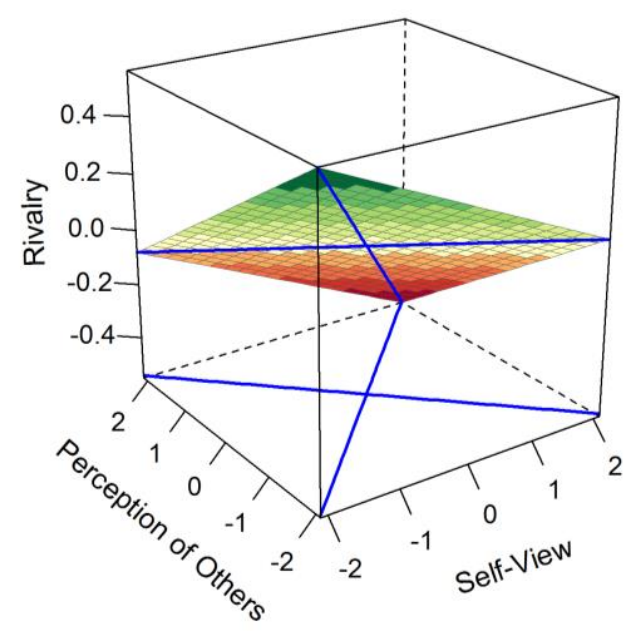

(d) Negative relation between Rivalry and PSV (and Perc. of Others) for Communion.

Figure 4. Plotted regression surfaces of the CRA using perceptions of others as the criterion (i.e., narcissism $=c_{0}+c_{1} *$ self-view $+c_{2} *$ perceptions of others $+\varepsilon$.). 


\section{Agency}

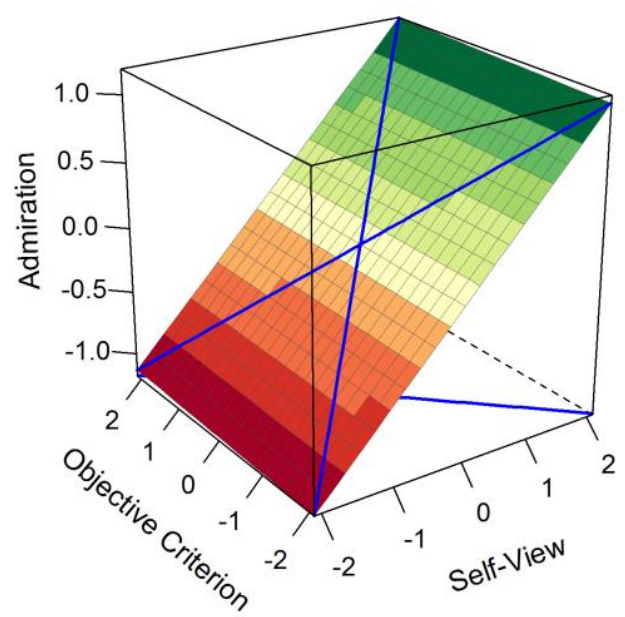

(a) Positive relation between Admiration and PSV for Agency.

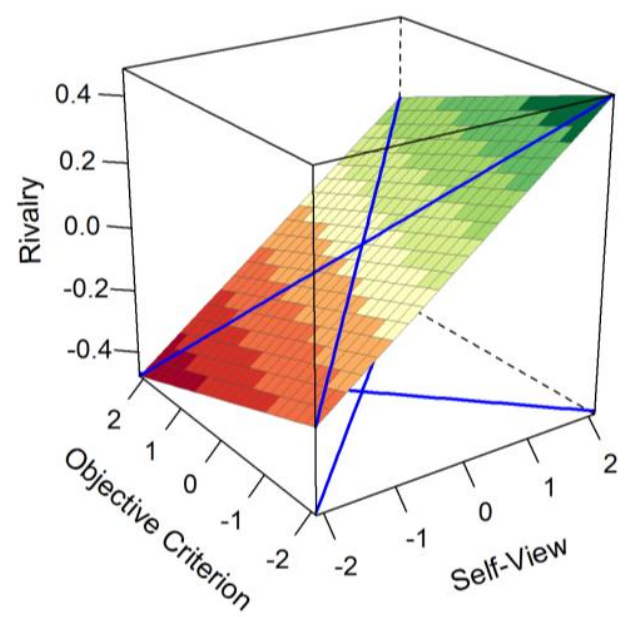

(c) Positive relation between Rivalry and PSV for Agency.

\section{Communion}

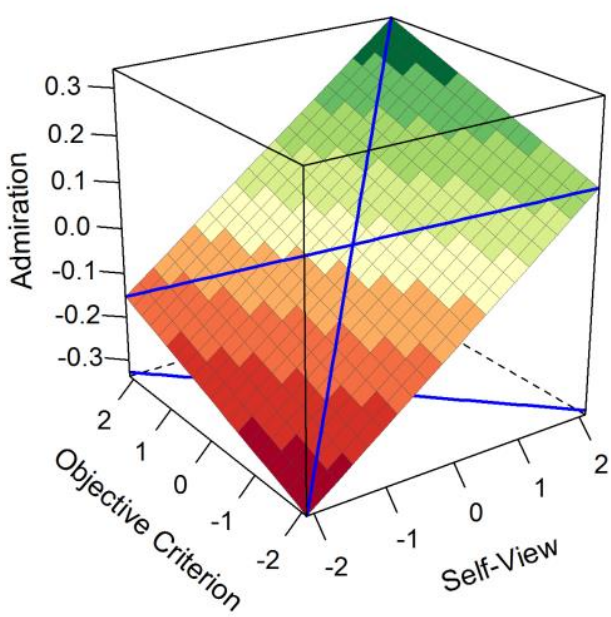

(b) Positive relation between Admiration and PSV for Communion.

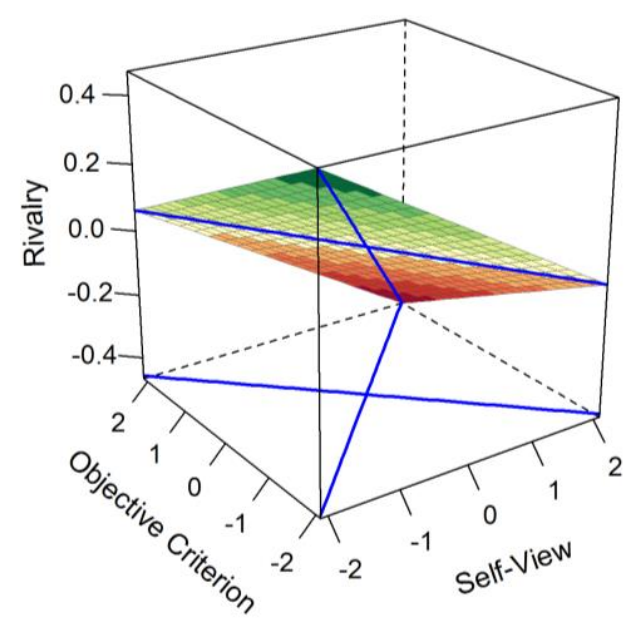

(d) Negative relation between Rivalry and PSV (and Obj. Criterion) for Communion.

Figure 5. Plotted regression surfaces of the CRA using the objective criterion (i.e., narcissism $=c_{0}+c_{1} *$ self-view $+c_{2} *$ objective criterion $+\varepsilon$.). 


\section{Discussion}

The aim of the present study was to disentangle narcissism's relations with SE and PSV. In contrast to prior research, we used a statistical approach that allowed us to distinguish between narcissism's associations with SE and with mere PSV. To better understand the potential boundary conditions of narcissistic self-evaluations, we considered (a) different aspects of narcissism (i.e., narcissistic admiration and rivalry), (b) different content domains of self-views (i.e., agency and communion), and (c) different criteria against which self-views were compared (i.e., reputations, perceptions of others, and objective measures).

Our results did not indicate a general robust relation between narcissism and SE. However, admiration was related to SE when comparing participants' self-views of agentic or communal characteristics with corresponding reputations. Rivalry was related to SE when comparing participants' self-views of agentic characteristics with reputations and with their perceptions of others' agentic characteristics. In all other cases, we identified significant relations between narcissism and PSV, although the directions differed between the aspects of narcissism and the domains. Admiration was consistently positively related to PSV across both domains, whereas rivalry was consistently negatively related to PSV in the communal domain, and only in one case (objective comparison criteria) it was positively related to PSV.

The present results provide initial insights into narcissism's associations with SE when disentangling these from narcissism's associations with PSV. In contrast to the general characterization of narcissism as the "self-enhancer personality," associations with SE were revealed in only four out of 12 analyses. Thus, whether narcissism is related to SE seems to depend on the aspect of narcissism under consideration, the self-view content domain, and the comparison criterion. Future research is therefore well-advised to treat individual differences in narcissism and SE as separate constructs and to closely consider the boundary conditions under which they converge or not. 
The most consistent evidence of a positive association between narcissism and SE was found when self-views were compared with reputations from well-known acquaintances (SE effects in three out of four analyses). This might indicate that narcissistic SE is first and foremost a socially construed phenomenon. Whereas narcissistic individuals view themselves more positively, this might only make them "self-enhancers" when compared with others' views but not when compared with their own views of others or with their actual performances and behaviors. The discrepancy between narcissists' self-view and other's view on them might also play a role in narcissists' popularity. Prior research on narcissists' popularity report a negative relation between narcissism and popularity among wellacquainted people (e.g., Czarna, Leifeld, Śmieja, Dufner, \& Salovey, 2016; Paulhus, 1998). The negative impression narcissists make on acquaintances might be driven by their tendency to self-enhance, or, on the other hand, narcissists might exaggerate their self-view as a consequence of their lower popularity to maintain their grandiose self. One finding that account for the latter is that narcissists seem to be aware of the existing gap between their self-perceptions and perceptions of others (Carlson, Vazire, \& Oltmanns, 2011). However, the present findings are not able to clarify this question but offer exciting perspectives for future research on narcissistic SE that include the focus on narcissists' mental processes as well as on social interactions. Specifically, it might be crucial to better understand why social partners' perceptions of narcissists tend to be more negative than narcissists' own perceptions. This would call for fine-grained investigations of the expression of behavioral cues related to narcissism and how these cues are perceived and evaluated by social partners and (more or less narcissistic) actors themselves (Leckelt, Küfner, Nestler, \& Back, 2015; Leckelt et al., 2020). Moreover, it is possible that the relation between narcissism and SE depends on the level of comparison criterion and that the involved processes vary for different manifestations of the criterion. Taking upon this idea, different processes might in turn be present at different 
levels of the continuous SE scale. As the present study did not examine processes that lead to the presence or absence of narcissistic SE, this question needs to be addressed in future research.

Another noteworthy finding concerns the different aspects of narcissism. Here, findings converged for only two of the six analyses. These results underline the need to distinguish between agentic (admiration) and antagonistic (rivalry) aspects of narcissism when interests lie in the intra- and interpersonal correlates and dynamics of grandiose narcissism (Back, 2018; Back, Küfner, \& Leckelt, 2018). Results for the NPI further show that a one-dimensional measure is not able to show differentiated findings and that the NPI represents mostly agentic and only sparse antagonistic aspects of narcissism (e.g., Brown, Budzek, \& Tamborski, 2009). An even clearer pattern emerged when additionally considering the content domain, with more similar results regarding agentic content and rather divergent results for communal content. For agency, four of the six analyses indicated comparable results for admiration and rivalry (indicating positive SE or PSV effects). However, selfperceived agency was stronger related to admiration than to rivalry. Differences for communion were more accentuated. Whereas admiration was positively related to selfperceived communion, rivalry was negatively related to it. These results are in line with previous results in which admiration was found to be related to positive agentic self-views and rivalry to negative communal self-views (Back et al., 2013; Kwiatkowska et al., 2019; Mota et al., 2019).

Future research needs to investigate the generalizability of the present results. Both samples in the present research consisted of young and highly educated Western students. Moreover, we focused solely on grandiose narcissism. Accordingly, we do not yet know whether vulnerable narcissism, pathological forms of narcissism (Cain, Pincus, \& Ansell, 2008; Miller et al., 2011), or more content-specific forms of narcissism such as communal 
narcissism (Gebauer, Sedikides, Verplanken, \& Maio, 2012) are related to SE or to PSV. Future applications of the present multimethodological and CRA approach might reveal general and sample-dependent conditions of the relation between narcissism and SE. Given that a very large number of studies on narcissism and SE already exist (for a meta-analysis, see Grijalva \& Zhang, 2015), joining forces and applying the present analytical strategy to a huge collectively assembled data set seems to be the most reasonable and straightforward way to move forward. In this way, the research community will quickly derive a solid foundation for more fine-grained process analyses on narcissistic SE.

\section{Conclusions}

The present study shed light on the long-assumed close link between grandiose narcissism and SE. Evidence for such a link was revealed only under specific circumstances and most robustly when considering narcissistic admiration. These results call for a reconsideration of the state of research on narcissism and SE. Collective efforts are needed to reanalyse existing data and obtain more robust insights about the whens and whys of narcissistic SE. Specially, future studies are well advised to use a one-step analytical approach such as the CRA and to differentiate between aspects of narcissism, content domains, and comparison criteria. 


\section{References}

Alicke, M. D., \& Sedikides, C. (Eds.). (2011). Handbook of self-enhancement and selfprotection. New York, NY: Guilford Press.

Asendorpf, J. B. (1988). Individual response profiles in the behavioral assessment of personality. European Journal of Personality, 2, 155-167.

Asendorpf, J. B. \& Ostendorf, F. (1998). Is self-enhancement healthy? Conceptual, psychometric, and empirical analysis. Journal of Personality and Social Psychology, 74(4), 955-966.

Back, M. D. (2018). The Narcissistic Admiration and Rivalry Concept. In A. D. Hermann, A. Brunell, \& J. Foster (Eds.), The Handbook of trait narcissism: Key advances, research methods, and controversies (pp. 57-67). New York, NY: Springer.

Back, M. D., Küfner, A. C., Dufner, M., Gerlach, T. M., Rauthmann, J. F., \& Denissen, J. J. (2013). Narcissistic admiration and rivalry: Disentangling the bright and dark sides of narcissism. Journal of Personality and Social Psychology, 105(6), 1013-1037.

Back, M. D., Küfner, A. C. P., \& Leckelt, M. (2018). Early impressions of grandiose narcissists: A dual-pathway perspective. In A. D. Hermann, A. Brunell, \& J. Foster (Eds.), The Handbook of trait narcissism: Key advances, research methods, and controversies (pp. 309-316). New York, NY: Springer.

Becker, B. J., \& Wu, M.-J. (2007). The synthesis of regression slopes in meta-analysis. Statistical Science, 22(3), 414-429.

Bleske-Rechek, A., Remiker, M. W., \& Baker, J. P. (2008). Narcissistic men and women think they are so hot-But they are not. Personality and Individual Differences, 45(5), 420424.

Brown, J. D. (1986). Evaluations of self and others: Self-enhancement biases in social judgments. Social Cognition, 4(4), 353-376. 
Brown, R. P., Budzek, K., \& Tamborski, M. (2009). On the meaning and measure of narcissism. Personality and Social Psychology Bulletin, 35, 951-964.

Cain, N. M., Pincus, A. L., \& Ansell, E. B. (2008). Narcissism at the crossroads: Phenotypic description of pathological narcissism across clinical theory, social/personality psychology, and psychiatric diagnosis. Clinical Psychology Review, 28(4), 638-656.

Campbell, W. K., Reeder, G. D., Sedikides, C., \& Elliot, A. J. (2000). Narcissism and comparative self-enhancement strategies. Journal of Research in Personality, 34(3), 329-347.

Carlson, E. N., Vazire, S., Oltmanns, T. F. (2011). You probably think this paper's about you: Narcissists' perceptions of their personality and reputation. Journal of Personality and Social Psychology, 101, 185-201.

Crowe, M. L., Lynam, D. R., Campbell, W. K., \& Miller, J. D. (2019). Exploring the structure of narcissism: Toward an integrated solution. Journal of Personality, 87(6), 1151-1169.

Czarna, A. Z., Leifeld, P., Śmieja, M., Dufner, M., \& Salovey, P. (2016). Do narcissism and emotional intelligence win us friends? Modeling dynamics of peer popularity using inferential network analysis. Personality and Social Psychology Bulletin, 42(11), 15881599.

Denissen, J. J. A., Schönbrodt, F., van Zalk, M. H. W., Meeus, W. H. J., \& van Aken, M. A. G. (2011). Antecedents and consequences of peer-rated intelligence. European Journal of Personality Psychology, 25(2), 108-119.

Edwards, J. R. \& Parry, M. E. (1993). On the use of polynomial regression equations as an alternative to difference scores in organizational research. Academy of Management Journal, 36(6), 1577-1613.

Gabriel, M. T., Critelli, J. W., \& Ee, J. S. (1994). Narcissistic illusions in self-evaluations of intelligence and attractiveness. Journal of Personality, 62(1), 143-155. 
Gebauer, J. E., Sedikides, C., Verplanken, B., \& Maio, G. R. (2012). Communal narcissism. Journal of Personality and Social Psychology, 103(5), 854-878.

Griffin, D., Murray, S., \& Gonzalez, R. (1999). Difference score correlations in relationship research: A conceptual primer. Personal Relationships, 6(4), 505-518.

Grijalva, E., Harms, P. D., Newman, D. A., Gaddis, B. H., \& Fraley, R. C. (2015). Narcissism and Leadership: A Meta-Analytic Review of Linear and Nonlinear Relationships. Personnel Psychology, 68(1), 1-47.

Grijalva, E., \& Zhang, L. (2015). Narcissism and Self-Insight: A Review and Meta-Analysis of Narcissists' Self-Enhancement Tendencies. Personality and Social Psychology Bulletin, 42(1), 3-24.

Humberg, S., Dufner, M., Schönbrodt, F. D., Geukes, K., Hutteman, R., van Zalk, M. H. W., Denissen, J. J. A., Nestler, S., \& Back, M. D. (2018a). Enhanced versus simply positive: A new condition-based regression analysis to disentangle effects of self-enhancement from effects of positivity of self-view. Journal of Personality and Social Psychology, 114(2), 303-322.

Humberg, S., Dufner, M., Schönbrodt, F. D., Geukes, K., Hutteman, R., van Zalk, M. H. W., Denissen, J. J. A., Nestler, S., \& Back, M. D. (2018b). Why Condition-Based Regression Analysis (CRA) is Indeed a Valid Test of Self-Enhancement Effects: A Response to Krueger et al. (2017). Collabra: Psychology, 4(1), 26.

John, O. P. \& Robins, R. W. (1994). Accuracy and bias in self-perception: Individual differences in self-enhancement and the role of narcissism. Journal of Personality and Social Psychology, 66(1), 206-219.

Judge, T. A., LePine, J. A., \& Rich, B. L. (2006). Loving yourself abundantly: relationship of the narcissistic personality to self-and other perceptions of workplace deviance, 
leadership, and task and contextual performance. Journal of Applied Psychology, 91(4), $762-776$.

Krueger, J. I., \& Wright, J. C. (2011). Measurement of self-enhancement (and selfprotection). In M.D. Alicke \& C. Sedikides (Eds.), The handbook of self-enhancement and self-protection (pp. 472-494). New York, NY: Guilford.

Kwan, V. S. Y., John, O. P., Robins, R. W., \& Kuang, L. L. (2008). Conceptualizing and assessing self-enhancement bias: A componential approach. Journal of Personality and Social Psychology, 94(6), 1062-1077.

Kwiatkowska, M. M., Jułkowski, T., Rogoza, R., Żemojtel-Piotrowska, M., \& Fatfouta, R. (2019). Narcissism and trust: Differential impact of agentic, antagonistic, and communal narcissism. Personality and Individual Differences, 137, 139-143.

Leckelt, M., Geukes, K., Küfner, A. C. P., Niemeyer, L. M., Hutteman, R., Osterholz, S., Egloff, B., Nestler, S. \& Back, M. D. (2020). A longitudinal field investigation of narcissism and popularity over time: How agentic and antagonistic aspects of narcissism shape the development of peer relationships. Personality and Social Psychology Bulletin, 46, 643-659.

Leckelt, M., Küfner, A. C. P., Nestler, S., \& Back, M. D. (2015). Behavioral processes underlying the decline of narcissists' popularity over time. Journal of Personality and Social Psychology, 109(5), 856-871.

Lehrl, S. (1995). Mehrfachwahl-Wortschatz-Intelligenztest (MWT-B). Göttingen: Hogrefe.

Miller, J. D., Hoffman, B. J., Gaughan, E. T., Gentile, B., Maples, J., \& Keith Campbell, W. (2011). Grandiose and vulnerable narcissism: A nomological network analysis. Journal of Personality, 79(5), 1013-1042. 
Morf, C. C., Horvath, S. \& Torchetti, L. (2011). Narcissistic self-enhancement. Tales of (successful?) self-portrayal. In M. D. Alicke \& C. Sedikides (Eds.), The handbook of self-enhancement and self-protection (pp. 399-424). New York: Guilford Press.

Mota, S., Leckelt, M., Geukes, K., Nestler, S., Humberg, S., Schröder-Abé, M., ... Back, M. D. (2019). A comprehensive examination of narcissists' self-perceived and actual socioemotional cognition ability. Collabra: Psychology, 5(1), 6.

Oberauer, K., Süß, H. M., Schulze, R., Wilhelm, O., \& Wittmann, W. W. (2000). Working memory capacity — facets of a cognitive ability construct. Personality and Individual Differences, 29(6), 1017-1045.

Paulhus, D. L. (1998). Intrapersonal and intrapsychic adaptiveness of trait self-enhancement: A mixed blessing? Journal of Personality and Social Psychology, 75(5), 1197-1208.

Pelham, B. W., \& Swann, W. B. (1989). From self-conceptions to self-worth: On the sources and structure of global self-esteem. Journal of Personality and Social Psychology, $57(4), 672-680$.

R Core Team (2017). R: A language and environment for statistical computing. Vienna, Austria: R Foundation for Statistical Computing. Retrieved from: https://www.Rproject.org/.

Raskin, R., \& Hall, C. S. (1979). A narcissistic personality inventory. Psychological Reports, 45(2), 590 .

Rosseel, Y. (2012). Lavaan: An R package for structural equation modeling and more. Journal of Statistical Software, 48(2), 1-36.

Schütz, A., Marcus, B., \& Sellin, I. (2004). Die Messung von Narzissmus als Persönlichkeitskonstrukt: Psychometrische Eigenschaften einer Lang- und einer Kurzform des deutschen NPI. [Measuring narcissism as a personality construct: 
Psychometric properties of a long and a short version of the German Narcissistic Personality Inventory]. Diagnostica, 50(4), 202-218.

Wallace, H. M. (2011). Narcissistic self-enhancement. In W. K. Campbell and J. Miller (Eds.), Handbook of narcissism and narcissistic personality disorder: Theoretical approaches, empirical findings, and treatment (pp. 309-318). Hoboken, NJ: Wiley.

Wright, A.G.C., \& Edershile, E.A. (2018). Issues resolved and unresolved in pathological narcissism. Current Opinion in Psychology, 21, 74-75. 


\section{Footnotes}

${ }^{1}$ We refer to SE as a dimensional trait, continuously ranging from negative SE (selfdefacement) to zero SE (accurate self-perception) to positive SE. Accordingly, PSV also follows a continuous scale and ranges from a very unfavorable to a very favorable self-view.

${ }^{2}$ Please note that controlling for the self-view in a regression of narcissism on SE does not solve the problem, because in this model, the coefficient of the SE score would reflect the effect of the criterion and not of SE (see Footnote 11 in Humberg et al., 2018a). 